\title{
The Analysis of Implementation and Implementing Strategy of Multilateral Development in Sport Training Sessions on Young Athletes in Indonesia
}

\author{
Ria Lumintuarso \\ Study Program of Sport Coaching, Faculty of Sport Science, State University of Yogyakarta, Yogyakarta, Indonesia
}

Received October 6, 2020; Revised November 11, 2020; Accepted December 22, 2020

\section{Cite This Paper in the following Citation Styles}

(a): [1] Ria Lumintuarso, "The Analysis of Implementation and Implementing Strategy of Multilateral Development in Sport Training Sessions on Young Athletes in Indonesia," International Journal of Human Movement and Sports Sciences, Vol. 8, No. 6, pp. 428 - 437, 2020. DOI: 10.13189/saj.2020.080615.

(b): E Ria Lumintuarso (2020). The Analysis of Implementation and Implementing Strategy of Multilateral Development in Sport Training Sessions on Young Athletes in Indonesia. International Journal of Human Movement and Sports Sciences, 8(6), 428 - 437. DOI: 10.13189/saj.2020.080615.

Copyright $@ 2020$ by authors, all rights reserved. Authors agree that this article remains permanently open access under the terms of the Creative Commons Attribution License 4.0 International License

\begin{abstract}
This research gives the description about the implementation and implementing strategy of multilateral development in sport training session on young athletes in Indonesia. This research is designed by action research approach and using action intervention such as learning package by multilateral approach. The subjects of the research are the fourth-grade students joining co-curricular program in school consisting 20 student-athletes with the program activity schedule which has been determined. The data analysis was done by describing the data collection through observation and interview from various sources. On the result description, it is elaborated that the multilateral learning model, schematic picture of multilateral learning model is a sport learning program based on multilateral development consisting the summary and the elements of basic movement and the basic sport technical movement integrally in one learning session. Development model following the normal learning flow such as: opening, essence and closing. The Multilateral Learning Model is an alternative learning strategy which can be used by physical education teachers in elementary schools to provide better solutions for the implementation of physical education as the foundation of future life development both related to physical freshness and sports mobility skills. Therefore, in adult aged, students will have readiness to live their lives, both in life leading to sporting achievements and in the life of other professions.
\end{abstract}

Keywords Multilateral, Sport, Athlete Coaching

\section{Introduction}

Multilateral development is a development based on movement freedom on the child as an effort of a broad base in prestige coaching in the future. The important of multilateral development has been recognized by the experts which are marked by the existence of multilateral development in the pyramid of coaching system as done by Bompa, Thompson as well as other experts [1,2].

The experts have elaborated and suggested to design a long-term and continuously training through a clear training stage. Reaching an optimal prestige, the training should be started from base multilateral training, advanced training and development training. However, the question is, if the implementation in the field has been suitable for the concept, and it needs to be further studied.

The gap between the concepts above with the application in the field is still shown by the number of some athletes who cannot reach the optimal performance in their golden age. Spartan, ambition and lack of responsibility toward young athletes cause several bad consequences. We often find some potential athletes got the injury and causing them to leave the sport. Lange [3] states that when some young athletes suffer from dangerous disease (osteoporosis, heart, etc.) it is caused by a hard training prematurely which make the drop-out phenomenon. 
Meanwhile, the competition system developed by several sport organizations and other institutions tend to have no impact on multilateral development. The competition in children group is often too exclusive and oriented to the achievement branch or certain sport number, therefore young children do limited development at the young age. Even, it looks like a such competition between one sport with another to recruit young people into their sport by providing specialized training and competition.

The campaign of long-term and sustainable training programs through the right stages cannot be done only by oration, lecture and advice through scientific books and blaming the trainer, but it is necessary to implement an action that provides awareness and creates the need for all parties to implement a system of proper development implementation through a long-term and tiered process based on the process of growth and development from children to adulthood.

An indication of the unpreparedness of regeneration from previous generations to the younger generation, especially in Indonesian athletes to excel in sports is Indonesia's achievement at the Southeast Asian Games or SEA Games since 1999 Indonesia's achievements have decreased if not want to be called a downturn. From the SEA Games in 1977, Indonesia always got first ranked. Since sea games xx in 1999 in Brunei Darussalam until SEA Games XXII in 2003 in Vietnam, Indonesia had only been able to finish third.

In 2005 at the SEA Games XXIII in Manila, Indonesia ranked in fifth number. Then at SEA Games XXIV Indonesia came back in fourth place. Medal scoring has decreased with percentage at the 2009 SEA games in Laos, although Indonesia's order has improved to the third place (2008). In 1990 Asian Games XI event in China, Indonesia was ranked 7th, but at the 2002 Asian Games XIV in South Korea, Indonesia was only able to rank 14th, even in Doha Qatar Indonesia stumbled in 22nd. At Sydney Olympic games in 2000, Indonesia was ranked 37th, above Thailand which was ranked 46th and Vietnam as at 64th. In Athens in 2004, Indonesia dropped to 48th, below Thailand which was ranked 25th and Vietnam was at 317th [4]. This case shows that Indonesian sport achievements at regional and international level is on the decline and left behind the neighbouring countries that their position were below us. This fact is a big question mark for The Nation of Indonesia, whether these cases occur due to the multidimensional crisis in Indonesia since 1998, or because of the bad coaching, or because of the physical education system in schools that cannot provide a good foundation on the coaching of subsequent achievements.

Multilateral coaching which is also called multi-skill is the development of various skills and motor abilities with the adaptation of various training load needs to develop a thorough adaptation [5]. This means that every child at a young age needs multilateral skills coaching as foundation of the movement needed to build good physical freshness and prepare for motor skills training towards further development in achievement sports. By the development of all these aspects will be integrally achieved harmonious body portion. A child with a strong multilateral foundation will be able to achieve his sporting performance better than a child who does not have this foundation [6]. Multilateral coaching becomes important when a child is faced with a wide selection of physical activities both in school and in sports societies. The children often fail to determine the most appropriate choice to determine which physical and sporting activity best suits for their potential. Therefore, it is crucial for the children to try to do various physical activities besides as based all over the body and to understand the potential of their ability in various physical activities. This case is reinforced by the opinions of Gabbard, LeBlanc, and Lowy [7] et. Al which state that, multilateral development in the skill development phase as movement variability, where the movement variability is the provision of a variety of motion experiences with a particular theme. By the provision of this movement variability experience, children will have stronger patterns and motion awareness to be able to perform more efficiently in a variety of different situations.

Balyi and Hamilton [8] stated that the development of sporting achievements is an accumulation of the physical quality, technique, tactics and maturity of sportsmen who are systematically prepared through the correct coaching process. The success of the achievement of sports achievement is determined by various factors, one of them is the level of exercise according to the age level of the child. Sharkey grouped the training tiers into 4 stages based on age: learning basic skills, variety of skills, specific training, and high intensity training. According to Sharkey [9] The learning basic skill stage is the basic stage to build the foundation of sportsman skills, so this stage needs to get serious attention. At this stage the child is conditioned to be able to develop physical qualities, as well as techniques in the age of sports specialization.

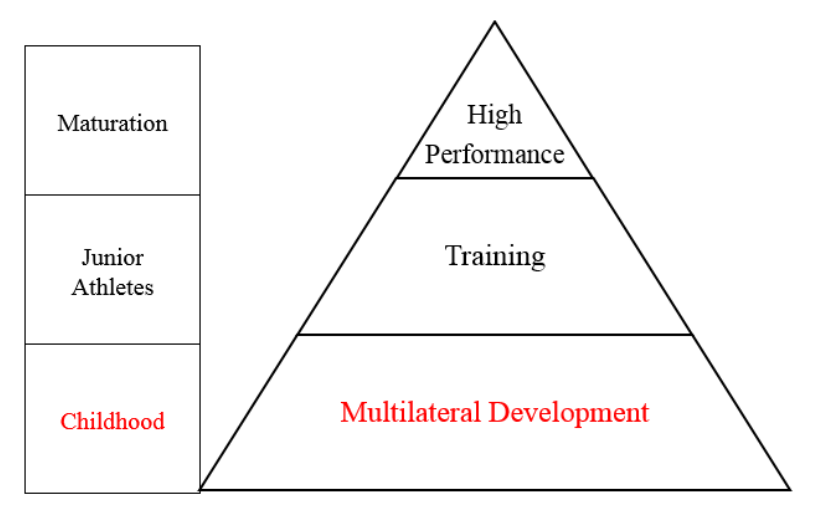

Figure 1. Multilateral Development (Bompa, 2000) [1]

From the description and Figure 1 above, it can be formulated that multilateral development is a comprehensive development in children's phase 
(Childhood) related to the development of various physical conditions and sports skills (skills) as the foundation towards special development (specialization) and high achievement.

Relating to the coaching foundations at a young age, Thumm [10] stated that, one of the biggest problems in sports coaching in developing countries is the weakness of early childhood coaching that has not been properly systemized. This causes athletes at high achievement levels become unstable and prone to fluctuating.

Characteristics for coaching having broad foundations are: it takes longer to achieve but it is more stable, the best achievement is achieved in adulthood, the risk of minor injuries, fewer drop outs, high levels of mastered technique, greater opportunities to choose alternative numbers or sports according to their potential. Therefore, broad foundation is the best system for athletes as a medium to achieve achievements with the lowest risk and can maintain their achievements for a long and stable period of time.

From the multilateral definitions discussed above, the multilateral motion is an amalgamation of various and basic motions of sports skills [11,12]. The basic motion is divided into three main types of motion, such as: locomotor, non-locomotor and manipulative. Kogan [13] and Nasution, Sunarno, and Kasih [14] simply describe the movement of the locomotor: "go somewhere" i.e. moving across space and distance by running, skipping, jumping, twisting walking, prancing and so on. Non- locomotor motion is a motion in which only the body part moves such as swinging and twisting the arm, pushing, pulling, leaning, and so on. Kogan [13] gave a simple limitation: "movements are those that stay in one place". This means that unlike the motion of the locomotor, the non- locomotor motion is carried out in a place of no displacement. Manipulative motion [14] can be done with other combinations of motion such as locomotor motion and non- locomotor motion. At the initial learning level all of the above movements are carried out with limited motion, which is given more complexly. Purely non-locomotor, non-locomotor and manipulative motion in the early stages is given as a basic movement to strengthen the enrichment of motion in children.

Implementing multilateral programs in sports which are variety of motions and skills, is certainly inevitable from the use of necessary sports facilities. This equipment is essential to carry out various physical activities with various movements oriented towards the existing sports. "Children are not small adult version" [15,2] have different characters to adults both in terms of body size and mental abilities. Therefore, handling the children need to adapt all related aspects such as: how to communicate, how to teach something or customize the equipment used for children.

Indonesia, through the cooperation among the universities and the Directorate General of Sports, the Ministry of National Education conducted research to create sports equipment for children based multilaterally in 2003-2005. The study found that a set of children's sports equipment was packaged in a package with eleven types of equipment. Children's Sports Equipment (POA) has now been used in primary schools in Indonesia as a medium of physical education learning and is also used as equipment for the National School Sports Olympic Festival (OOSN) at the elementary and ASEAN Primary School Sport Olympic (APSSO) level. This children sports device has specificity compared to Kids Athletics, Fun in Athletics and Mini Tennis devices as well as other equipment. At Kids Athletics and Fun in Athletics, equipment is limited to athletic sports for use in running, jumping and throwing numbers. Mini tennis is used for children's tennis games, while the POA contains equipment that can be used for various sports such as all athletic numbers, sports with rackets, sports with balls and sports with other tools.

Multilateral coaching is a foundation that must be instilled in the process of coaching sporting achievements. Therefore in every physical activity, whether in the concept of training in sports associations or in the learning process of physical education at a young age, multilateral coaching is a necessity to be implemented. The Multilateral Learning Model (MPM) in this study can be interpreted as an example of a form of learning with a multi-skill approach and motor skills in one session that is expected to be applied in young athlete training session situations.

The aim of this research is conducting the implementation analysis and describing the development strategy of multilateral coaching in sport training session on young athlete in Indonesia.

\section{Research Method}

This research is designed with an action research approach that uses action interventions in the form of learning packages with a multilateral approach. Actions are designed into multiple cycles until the objectives/effectiveness of the model can be achieved. The technique of data retrieval in this action research can be done through two ways, namely experiencing which include observation and field recording and examining, namely by using archive data sources, journals, audio, and video as well as field records that are required only at the stage of implementation of the action. The subjects of the study are 4th grade participated in a co-curricular program at the school of 20 student-athletes with the schedule of activities had been determined.

Action research is designed several cycles until the aim/effectivity of model can be reached. The number of action cycles are determined based on the problem finished or the goal which will be achieved. If at the first cycle can be finished, the second cycle is not needed. Meanwhile, if the first cycle cannot be finished, the second cycle and so on should be conducted. The design of action cycle in this 
research has four alternatives as follow:

1. Action plan, designing training material by the multilateral principle on twelve years old. It is needed several basic motions of sports with the composition produced in this research on the first part with several alternatives.

2. The action implementation by applying the model found with the development of its alternative action suitable for condition occurring.

3. Observation, do the observation of each event in the field by taking note of the data.

4. Analysis and reflection, analysis is done on the cycle being implemented to reduce the data, explanation and conclusion of the data obtained. Reflection is done to analyse the result whether the problem has been solved or it needs the next cycle with another action.

The data analysis was conducted descriptively through observation and interview from various sources. Data analysis covers data reduction, data explanation and conclusion. After conducting the analysis, then the data is interpreted analytic descriptively. This analysis is used to know if the intervention is implemented well as a training model with multilateral approach by applying the criteria of trustworthiness for qualitative research (including action research) include credibility transferability, dependability, dan confirmability.

\section{Results and Discussion}

The development of the training model is a continuous and continuously changing long-term process, as the development of the exercise model is related to the development of the athletes, the model must be evacuated and modified continuously in a view of the science response, the level of athletes' development and the measurement of the athletes' progress. The development of the training model is begun by analyzing in detail the sports science literature with the physical characteristics of athletes [17]. Some of the findings above are supported by several theories, among others according to Hidyah [18], stating that at the final school age stage (15 - 18 years) is more special stage of training because it will go through the beginning of career achievement. Therefore, technical refinement and skills improvement should be more considered with the support of excellent physical ability results. Physical ability at this age should be an important concern for trainers because excellent physical ability will help the process of refining techniques to become skilled and automated. From that opinion, the multilateral training model will provide better exercise results if it is applied in the process of training especially to extracurricular activities. In fact, the weight of exercise serves as a stimulus and brings a response from the athlete's body. If the weight of exercise is heavier than the normal weight of the body then the body will experience fatigue so that the fitness level will become lower than the normal fitness level. This will require a longer recovery period. It means, the charging will cause fatigue, and when the burden expires, the recovery occurs. Each training process requires objectives and objectives to be achieved. Training goals are required as guidelines and directions that are referenced by both coaches and athletes in running the training program. The goal of early-stage training according to Ambarukmi and Dwi [19] is multilateral development, i.e. athletes need a thorough physical development in the form of fitness as the basis for developing other aspects necessary to support their achievements.

The goal of training children at the elementary school level lies in multilateral development, i.e. overall physical development. A gradual approach to the development of athletes with multilateral principles towards specialization exercises in accordance with maturity is a requirement in maximizing the appearance of athletes [17]. The development of the training model is a continuous and continuously changing long-term process, as the development of the exercise model is related to the development of the athlete, the model must be evacuated and modified continuously in view of the science response, the level of athlete development and the measurement of the athlete's progress. The development of the training model begins by analyzing in detail the scientific literature of the sport with the physical characteristics of the athlete.

The research products include: Definition of Multilateral Learning Model, Schematic Image of Multilateral Learning Model, Multilateral Learning Model Procedure, and Precondition of implementation of Multilateral Learning Model.

\subsection{Definition of Multilateral Learning Model}

The Multilateral Learning Model is a physical education learning program based on multilateral development containing summary and elements of basic motion and the basis of technical motion as if it were an integral exercise in a single learning session.

In common with the concept of multilateral coaching also called multi-skill is the development of various skills and motor capabilities (motor ability Improvement) with the adaptation of various training load needs to develop a thorough adaptation [20]. This means that a child must have good and harmonious basic mobility skills.

\subsection{Session Procedure of Multilateral Learning Model are as follow:}

- The coaching model follows the normal learning flow: Opening/warm-up, core, and closing/ pacification

- Opening/warm-up is given a warm-up game with the aim of attracting the children's interest in carrying out 
lessons and raising your body temperature as well as avoiding injury.

- The core of the lesson, contains four units of sports games such as: (a) athletic or gymnastics games, (b) large ball games, (c) small-ball games, and (d) games with tools (rackets, bats, etc.), where each sports unit contains one type of game/movement. The four units are implemented sequentially with the allocation of time as available.

- Closing, given a relaxation game and or stalling to return students to normal conditions, ready to follow the next lesson

- Time sharing is determined by the teacher according to the availability of time in one physical education learning session in the elementary school.

\subsection{Pre-Condition of Multilateral Learning Model Implementation}

- MLM Basic of sports movement is provided for elementary school students of grade 3 to grade 6 , while for grade 1 and grade 2 can be given MPM based on basic motion that is not discussed in this study.

- MLM can be carried out in a wide area which is about 30 meters length or more and 20 meters width or more and can be done in a narrower place with a length below 30 meters and a width below 20 meters.

- Coaching needs to prepare multilateral learning sessions well especially related to the classroom management, time, equipment and places, materials and plans for the social and emotional formation of students.

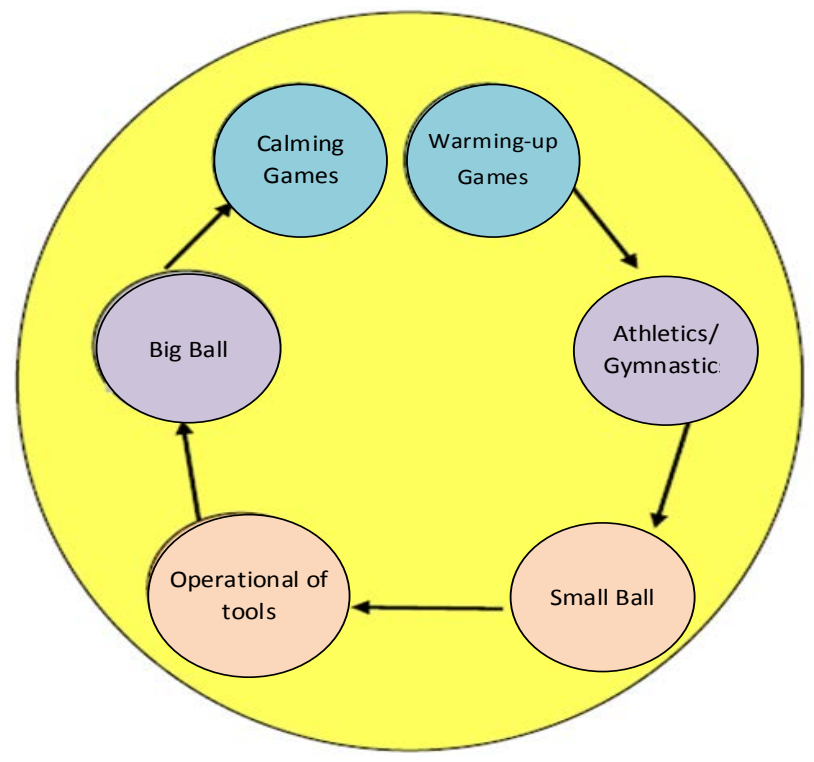

Figure 2. Final Schema Model

\subsection{Schematic Picture of Multilateral Learning Model}

From the implementation chart above, it can be concluded as follow:
Trainer can carry out the entire program in full planned and relative time is controllable and management equipment can run better.

- The warm-up game material corresponds to the first material in the core unit so that the coach feels easier manage the time, tools, and formation of the class (field). This helps teachers to control the course of exercise and the leeway of time to better observe and correct students individually.

The sequence of motion in one subject/unit of the game movement followed by the technique movement has made it easier for the teacher to direct the student's movements towards the desired motion. This sequence also motivates the child to make moves with the game first. The basic techniques of sports movement have begun to appear even though it is not stable because the child is still in the stage of movement recognition.

- The rotation of motion from one unit to the next which is always rotated in each session gives the children a joy, because it always gets different things in order and progressivity of the content.

- Motions performed by increasing difficult levels still often confuse the children because instruction and demonstration of movement by the trainer can sometimes not be clearly followed. A considerable number of children cause coaches to be unable to set examples many times due to time constraints.

- In General, the freshness of the children increases, according to the observation that the child is better able to survive with a better aerobic run at the end of the training session. This is reinforced by coaches/teachers during the training process and physical education learning in school, children look fresher and relaxed in making moves. As for the basic mastery of sports motion begins to appear technical form although not yet perfect.

\subsection{Action Implementation}

The implementation of this action is organized through several cycles to find the optimal results to be achieved. The prepared cycle is three cycles in which each cycle consists of several steps: (1). Action Planning, i.e. designing training materials with multilateral principles, (2) Implementation of actions by implementing a planned program, (3) Observation, i.e. observing every event in the field by recording data, and (4) Analysis and reflection, Analysis is performed on the cycle which is being implemented to reduce data, explaining and collecting the result of the data obtained. Reflections are performed to conduct a review of the results obtained whether the problem has been resolved or needs to be the next cycle by other actions.

\subsubsection{First Cycle Action}

The first cycle of action of this multilateral exercise 
program is planned two weeks with a frequency of three times per week. So in this first cycle there were six meetings with details: four training processes in the field and twice the physical education learning process at school each week. The program is called a micro cycle consisting of one week with three meetings. The process of implementing actions in this first cycle is carried out at the following stages:

\section{a. Action Planning.}

Action planning In the first cycle, researcher prepared the concept of an exercise program which is a result of multilateral learning products appropriated with the system and training program in one micro cycle. This planning is discussed with coach that will handle students and by peers can provide input, so that it is expected that the results of this program planning are absolutely appropriate and can be implemented in the field. As a result of the meeting with the coach, it was concluded that the coach can understand the concept of the multilateral training program and be ready to implement the established program with some input that is deemed necessary according to the ability of the existing students.

\section{b. Implementation Action.}

The program has been planned is conducted as follow:

- The first meeting, the exercise runs with the program planned. It starts at 3:30 p.m. and ends at 5:30 p.m. (120 minutes). All elements of the exercise can be implemented which is appropriate with the design of the program.

- Second meeting, 105 minutes of school learning from 07:00 am to 08:45 am. Teachers implement the multilateral learning programs in schools. All learning units can be implemented.

- The third meeting, the exercise runs with the planned program. Starting at 15:30 and ending at 17:20 (110 minutes). All elements of training can be implemented appropriate with the design of the program.

- The fourth meeting, the exercise runs with the planned program. Starting at $15: 30$ and ending at 17:20 (110 minutes). All elements of training can be implemented appropriate with the design of the program.

- Fifth meeting, 105 minutes of school learning from 07:00 AM to 08:45 AM. Teachers implement the multilateral learning programs in schools. All learning units can be implemented

- The sixth meeting, the exercise runs with the planned program. Starting at 15:30 and ending at 17:20 (110 minutes). All elements of training can be implemented appropriate with the design of the program

\section{c. Observation}

From the implementation program above, it is found several things, such as:

- Trainer can implement the entire program planned in full even with the uncontrollable time. (exceeding the 90-105-minute time plan).

- At the turn of the warm-up game to the first material is often inappropriate due to the differences in movement. For example the warm-up game uses a large ball but the first material is a sprint, so the children's movements are not transferred from warm-up to running motion. It also impacts on setting up more difficult tools so that more time is required.

- The sequence of motion in one subject/unit from movement technique to the movement does not provide the correct technical deepening of the motion, because the children at the stage of the game tends to concentrate on how to win the game, therefore they forget the basic techniques of motion they want to be achieved.

- During the three meetings observed, the children felt saturated with the same game branching sequence, so that in each meeting they had guessed what the teacher would give. This case seems less motivating for the child to get something new.

- The motion is volume-oriented, as the demands of the initial training stage can be implemented well and increased. At the end of the meeting the children felt too easy to make the moves, therefore the next step is necessary to increase the level of difficulty more.

\section{d. Reflection}

From the observation conducted by the researcher and coach as well peer above, it can be concluded as follow:

- Warming up game needs to be appropriated with the basic motion which will be done first so that the warming up material can directly fuse with the core material. It is intended to streamline time to be more provident.

- Each unit of motion is done by reverse order of the implementation above i.e. with the game first, then movement techniques.

- The order of units is recommended not performed randomly at each meeting, but it is conducted the rotation of the existing units. Therefore, the game on the warm-up can be various without reducing the connection of technical movements, and the children always get something new. 207

- The difficulty level of movement can be improved in the next cycle by slowly increasing the volume.

\subsubsection{Second Cycle Action}

As at the first cycle, the action at the second cycle of multilateral training program is planned in six times of meeting with details: four times training process in the field and twice learning process of physical education in school.

The process of implementation action in this second cycle are conducted by several stages, as follow: 


\section{a. Action Planning}

The researcher prepares the concept of training program by considering the result of discussion and reflection in the first cycle. This planning is discussed with the coach that will handle the students and peer students which can give suggestion and the result expected from the planning program is absolutely right and can be implemented in the field.

The meeting result with the coach, can be concluded that the coach can understand the concept of multilateral training program and ready to implement the program set by giving the observation of first cycle result, therefore it still has close relation with the first cycle, and the implementation in the field is easier for children to understand.

The action given in this second cycle are as follow:

- Warming up game is given suitable with the first unit.

- The sequence of the presentation multilateral units is always changed (rotation) in order to the warming up game can be variative.

- The sequence of the movement of each unit is organized with the game first and then technique.

- The difficulty level of the movement is improved

- Implementation Action

The program planned is implemented as follow:

- First meeting, (the $15^{\text {th }}$ day) the training runs with the program planned. It began from 15.30 and ends at 17.15. (105 minutes). All of the training elements can be implemented appropriated with the program designed.

- Second meeting, (the $17^{\text {th }}$ day) was implemented in physical education learning by multilateral model where its implementation is 105 minutes with the learning plan by the teacher.

- The third meeting, (the $19^{\text {th }}$ day) the exercise runs with the planned program. Starting from 15:30 and ending at 17:10 (100 minutes). All elements of training can be implemented appropriating with the design of the program.

- The fourth meeting, (the $22^{\text {nd }}$ day) the training runs with the planned program. Starting at 15:30 and ending at 17:00 (90 minutes). All of training elements can be implemented although in the last unit the implementation is not able to be perfect because the drizzle is starting to fall.

- The fifth meeting, (the $24^{\text {th }}$ day) is implemented in physical education learning with multilateral model where the implementation is 105 minutes with learning planned by the teacher.

- The sixth meeting, (the $26^{\text {th }}$ day) the exercise runs with the planned program. Starting at 15:30 and ending at 17:15 (90 minutes). All elements of the exercise can be implemented.

b. Observation

From the implementation program above, it can be found several things which can be summarized as follow:

- The coach can implement the entire program in full planned and relatively controllable time and management equipment can run better.

- The warm-up game material corresponds to the first material in the core unit so that the coach is easier to managing the time, tools, and formation of the class (field). This case helps teacher in controlling the training running and time leeway to observe more and correct students individually.

- The sequence of movement in one subject/unit of the game movement followed by the technique movement has made easier for teacher to direct student's movements towards movement direction they want. This sequence also motivates the children to make moves with the game first. The basic techniques of sports movement have begun to appear even though it is not stable since the children are still in the stage of movement recognition.

- The rotation of movement from one unit to the next which is always rotated in each session gives a pleasure for children, because they always get different things in order and progressivity of the content.

- Movement performed by increasing difficulty levels still often confuse the children because the instruction and demonstration of movement by the coach cannot be clearly followed. A considerable number of children make coach is unable to give the examples many times due to the limited time.

- In commonly, the freshness of the children increases, according to the observation that the children are better able to survive with a better aerobic running at the end of the training session. This is reinforced by coaches/teachers during the training process and physical education learning in school, children look fresher and relaxed in making moves. As for the basic mastery of sports movement begins to appear the technical form although it has been not yet perfect.

\section{c. Reflection}

From the observation conducted by the researcher and coach as well peers above, it can be concluded as follow:

- The program can already run properly in terms of implementation, time can be controlled by the coach, and corrections can be given better individually to the children. The achievement of fitness has also been better, this case appears from the quality / intensity of the children's movement which is still good until the end of the training session.

- In the unit of basic ability of sports movement, the children's ability still need to be improved by emphasizing on the important elements of movement such as: throwing position, position on jump, and active movement on running. From this observation, it is necessary to do additional information with visual 
media which can be seen by athletes at the time of doing the movement.

- The difficulty level of movement increasing needs to be followed by a higher intensity so that the achievement of movement results can be in line with the effort made, for example in throwing movement, done by giving a boundary of the line to the area where the throwing object should reach the area which then the distance is further.

- In big ball games and with tools (rackets), giving material towards the game with clear rules and number counts is introduced to get to the next stage of practice.

\subsubsection{Third Cycle Action}

The third cycle is the continuity from the second cycle. The implementation action process in this third cycle is conducted by several stages as follow:

\section{a. Action Planning.}

The researcher prepares the concept of training program as a follow-up from the second cycle by considering the result of discussion and reflection on the second cycle. This planning is discussed with the coach and peers that can give the suggestion therefore it is expected that the result of the planning can reach the goal wanted as follow:

- Increasing the time for game implementation.

- Attaching a picture of each children's movement technique while doing basic exercise movement so that they can see the correct movement.

- Increasing the intensity of movement by setting movement target, i.e. by target limits, far throws and jumps, running speed and appraisal on the game.

b. Implementation Action

The program has been planned is implemented as follow:

- The first meeting, (the $29^{\text {th }}$ day) the training runs with the planned program. Starting at 3:30 p.m. and ending at 5:15 p.m. (105 minutes). All elements of the training can be implemented appropriate with the design of the program.

- The second meeting, (the 31st day) are conducted in physical education learning with a multilateral model where its implementation is 105 minutes with learning planning by the teacher.

- The third meeting, (the $33^{\text {rd }}$ day) the training runs with the planned program. Starting from 15:30 and ending at 17:10 (100 minutes). All elements of the training can be implemented suitable with the design of the program.

- The fourth meeting, (the $36^{\text {th }}$ day) the training runs with the planned program. Starting at 15:30 and ending at 17:10 (100 minutes). All elements of training can be implemented properly.

- The fifth meeting, (the 38th day) are implemented in physical education learning with a multilateral model where the implementation is 105 minutes with learning planning by the teacher.

- Sixth meeting. (the $40^{\text {th }}$ day) the training runs with the planned program. Starting at 15:30 and ending at 17:10 (100 minutes). All elements of the exercise can be implemented properly.

\section{c. Observation}

From the implementation program above, it can be found several things which can be summarized as follow:

- The coach can perform the entire program in full and relative time can be controlled properly, the opportunity to correct (give feedback) can be further improved in this cycle.

- The targeting of movement makes the children more excited to implement their ability in movement.

- The high intensity of movement needs to be followed by a reduction in the volume of movement, therefore the children gets sufficient rest time to recover his condition.

- In general, it appears that the children have more skilled in performing various movements, the increasing of difficulty level begins to be adapted by the child. The image shown during the movement performance helps the children to understand more about the correct structure of movement.

- In general, the freshness of the children increases, appropriate with the observation where children are more able to survive with a better aerobic running at the end of the training session.

\section{d. Reflection}

From the observation conducted by the researcher and coach as well the peers above, it can be concluded as follow:

- The programs with the increasing of difficulty level of movement, the intensity and volume reduction can run well and children are able to adapt the movement quickly. This is an accumulation of learning processes at the first and second cycles as well as reinforcement in this third cycle.

- The coach can make better observation and correction/feedback when implementing basic motion techniques performed with target motion with a slightly reduced volume. In this third cycle, it appears that the atmosphere of the training process is different from in the physical education learning process with various increasing of movement mastery and intensity of movement.

- The basic mastery of sports movement with repetition and simple game has been mastered by the children even though the consistency/stability is new at the initial level. The training process can be improved in more specialized phase to finalize more the movement. 
- At the end of this third cycle, the researcher, coach and colleagues decided that the final test/post test could be done to determine the improvement of physical freshness and basic ability of the children's sports movement.

Supporting the research result above, that good sports activities for early childhood, should be appropriate with the children's growth and development and should be given a variety of comprehensive movement experiences (Multilateral Training) in the form of games and competition with a pleasant atmosphere [21]. Kids' Athletics program is a multilateral coaching program i.e. a process where in one training session contains various basic skills such as running, throwing, jumping, basic sports skills with big balls, small balls and sports with tools. Multilateral coaching programs are designed with various forms of presentation: games and competitions, individual and group work, simple application of disciplines and regulations, suitable equipment for the children's growth and development (Modifications), and various movement tasks to be implemented in student groups [20,22].

The Multilateral Learning Model (MLM) produced in this study is a learning strategy that can be applied to elementary school students in grades four, five and six. Since multilateral learning is tested using a basic training unit where the basic training movement base appropriate with the children between the ages of 10 and 14 . Meanwhile, for first grading to third grade elementary schools, at the age of seven to nine, still based on basic movement skills such as locomotor, non-locomotor and manipulative. Regarding from this case, teachers can do the analogues of multilateral learning processes based on the basic movement skills to be performed in the first, second and third graders. Another alternative to implement multilateral learning in first grade to third grade, teachers or researchers can conduct advanced researcher to test the Multilateral Learning Model with basic movement skills learning units for first- to third-grade. This is necessary because for first to third grade, it is still unknown the physical and mental abilities in facing of the number of units they have to do.

Relating to the place used in this multilateral learning. In wide place, the teacher can use freely in overall mainly in advanced meetings by preparing all of equipment on the posts have been organized before the learning began to be three, four or five posts together, therefore students can be divided into groups set in each post. In every time unit, teacher can perform the rotation from one post range to two post, three post and so on a circuit basis. This case can be performed due to the learning of students' test have known about what they should do in each post. Teacher can function as facilitator and perform the feedback and evaluation in a group and individual. On the limited place, teacher may be only able to organize two or more post during the implementation, therefore in every learning unit replacement, teacher should reorganize the equipment for the next unit. On the limited place, the obstacle in on time management. However, teacher can organize the use of equipment successively from one unit to the next unit with the same equipment, for instance: bracelet can be used for running unit relay, then enter to the throwing unit. For the narrow place, or in hostile situations, the activities must be implemented in a narrow place, teachers can implement activities by organizing one time one activity, so that the class or place is one post. Each teacher completes one post then he will implement the next post in the same place. In this situation, time management to manage students and places as well equipment is essential, so that the preparation of learning is absolutely necessary.

\section{Conclusion}

Extracurricular programs in schools is an expectation for students to deepen and discover their potential, therefore the coach need to help students or athletes' participants of extracurricular programs to underline with good basic skills to lead to the future development readiness and try more optimally in finding and developing students' talent towards the process of coaching sports achievement. Multilateral training program is a medium to achieve the conditions, so the coach need to prepare students test better appropriate with their growth and development. The Multilateral Learning Model is an alternative learning strategy which can be used by physical education teachers in elementary schools to provide better solutions for the implementation of physical education as the foundation of future life development both related to physical freshness and sports mobility skills. Therefore, in adult age students will have readiness to live their lives, both in life leading to sporting achievements and in the life of other professions.

\section{REFERENCES}

[1] Bompa, T. O. (2000). Total training for young champions: Human Kinetics.

[2] Thomson, B. (2013). First steps in coaching: SAGE.

[3] Lange, G. (1996). Striving for Performance: Coaching Female Athletes in Asia Women's Athletics Symposium.

[4] Olahraga, D. B.-D. (2004). Indikator olahraga Indonesia: Jakarta.

[5] George, M. D., Petcu; Cristian, Popa; Dorin, Ochiulet. (2014). Identification standard and non-standard exercises for multilateral physical training to soccer players beginners. Ovidiu's University Annals, Series Physical Education \& Sport/Science, Movement \& Health.

[6] Bompa, T. O., \& Buzzichelli, C. (2018). Periodization-: theory and methodology of training: Human kinetics. 
[7] Gabbard, C., LeBlanc, E., \& Lowy, S. (1994). Physical education for children: Building the foundation: Prentice-Hall.

[8] Balyi, I., \& Hamilton, A. (2004). Long-term athlete development: Trainability in childhood and adolescence. Olympic Coach, 16(1), 4-9.

[9] Sharkey, B. J. (1986). Coaches guide to sport physiology (Vol. 1): Human Kinetics.

[10] Thumm, H.-P. (1987). The Importance of the basic training for the development of performance. New Studies in Athletics, 1, 47-64.

[11] Lumintuarso, R. (2019). Multilateral Training Model in Sport Performance. Paper presented at the 2nd International Conference on Sports Sciences and Health 2018 (2nd ICSSH 2018).

[12] Popescu, F., Porfireanu, M.-C., \& Ristea, C. (2016). The interest of youth in sport activities. Ovidius University Annals, Physical Education and Sport/Science, Movement and Health Series, 16(2 Suppl.), 641-646.

[13] Kogan, S. (2003). Step by step: A complete movement education curriculum: Human Kinetics.

[14] Nasution, U., Sunarno, A., \& Kasih, I. (2020). Aquatic Sport Learning Through Multilateral Approaches. Paper presented at the 1st Unimed International Conference on Sport Science (UnICoSS 2019).
[15] De Maria, C. R. (1972). Movement Education: An Overview. Physical Educator, 29(2), 73.

[16] Meyer, F., O'Connor, H., \& Shirreffs, S. M. (2007) Nutrition for the young athlete. Journal of sports sciences, 25(S1), S73-S82.

[17] Nurulfa, R. (2017). Pengembangan Model Latihan Lari Cepat Berbasis Multilateral Untuk Anak Sekolah Dasar. Gladi: Jurnal Ilmu Keolahragaan, 8(1), 37-48.

[18] Hidyah, T. (2011). Latihan Multilateral Alternatif Untuk Meningkatkan Kondisi Fisik Pemain Bola Basket. Media Ilmu Keolahragaan Indonesia, 1(2).

[19] Ambarukmi, D. H., \& Dwi, D. (2007). Pelatihan pelatih fisik level 1. Jakarta: Kemenpora.

[20] Asep, A. (2018). Pengaruh Kids'athletics Terhadap Self-Esteem Dan Kebugaran Jasmani (Studi Expost Facto Pada Siswa Sekolah Atletik Pajajaran). Didaktik: Jurnal Ilmiah PGSD STKIP Subang, 4(1), 75-94.

[21] Oleksandr, K. (2014). Multilateral training: re-examining the concept's practicality/Oleksandr Krasilshchikov. Malaysian Journal of Sport Science and Recreation, 10(1), 1-15.

[22] de Haan, D. M. (2017). A Review of the Appropriateness of Existing Micro-and Meso-level Models of Athlete Development within Equestrian Sport. International Journal of Human Movement and Sports Sciences, 5(1), 1-8. 